\title{
Thermography Inspection for Early Detection of Composite Damage in Structures during Fatigue Loading
}

\author{
Joseph N. Zalameda*a, Eric R. Burke ${ }^{\mathrm{a}}$, F. Raymond Parker ${ }^{\mathrm{a}}$, Jeff P. Seebo ${ }^{\mathrm{b}}$, Christopher W. Wright ${ }^{\mathrm{a}}$, \\ and James B. Bly ${ }^{\mathrm{b}}$ \\ ${ }^{a}$ NASA Langley Research Center Hampton, VA 23681-2199; \\ ${ }^{\mathrm{b}}$ Lockheed Martin NASA Langley Research Center Hampton, VA 23681-2199
}

\begin{abstract}
Advanced composite structures are commonly tested under controlled loading. Understanding the initiation and progression of composite damage under load is critical for validating design concepts and structural analysis tools. Thermal nondestructive evaluation (NDE) is used to detect and characterize damage in composite structures during fatigue loading. A difference image processing algorithm is demonstrated to enhance damage detection and characterization by removing thermal variations not associated with defects. In addition, a one-dimensional multilayered thermal model is used to characterize damage. Lastly, the thermography results are compared to other inspections such as non-immersion ultrasonic inspections and computed tomography X-ray.
\end{abstract}

Keywords: thermal nondestructive evaluation (NDE), fatigue damage, composite delamination, matrix cracking

\section{INTRODUCTION}

In situ wide area inspection methods are required to determine damage initiation and growth in advanced composite structures during controlled load testing. The load testing is required for validation of test articles and structural analysis tools [1,2]. The significant damage modes for composite structures are delamination and matrix cracking. For a given composite design, understanding how damage initiates and grows improves confidence in predicting fatigue life. In this work, nondestructive evaluation (NDE) is used to detect the onset and growth of damage during controlled fatigue loading. The inspection is performed while the structure is on the load frame, and therefore does not require removal from a test fixture. This is more time efficient and removes potential errors due to handling induced damage if removed for inspection. Thermal NDE has been shown to be an effective technique for detecting damage in composites during load testing because the inspection is non-instrusive [3]. Thermography inspections performed on a composite cylinder and a hat stiffened composite panel are presented.

Two noncontact thermography techniques, passive and active, are used to detect the initiation and progression of damage in a composite cylinder during cyclic loading. The types of damage detected are matrix cracking and delaminations. The active flash thermography technique utilizes a flash tube enclosed within the cylinder and allows for the measurement of through-the-thickness diffusivity [4]. A small torsion load is applied (both clockwise and counterclockwise) during the flash thermography inspection and a difference thermography processing technique is applied to remove thermal variations associated with normal material variations [5-7]. It has been found that the combining the application of a static torsion load during the flash inspection with difference processing improves defect contrast and helps to size the defects [6].

In addition, a passive thermography technique is used on both the composite cylinder and hat stiffened composite panel. This method detects and tracks damage progression in real time as dynamic loading is applied. The loading will cause damaged areas to rub or clap together, thus providing frictional heating that is detected with an infrared camera [3]. The passive technique can provide a real-time indication of damage formation and growth. This information is used to determine when to stop the loading in order to perform a non-immersion ultrasound inspection [8]. The thermography

*joseph.n.zalameda@nasa.gov; phone 1 757-864-4793; fax 1 757-864-4914; http://researchtech.larc.nasa.gov/branches/nondes_eval_sci.htm 
results are periodically compared to non-immersion ultrasonic inspections. After completion of the fatigue loading, the test article was removed and X-ray computed tomography was performed. The thermography results are also compared to the X-ray results.

\section{SAMPLE DESCRIPTIONS}

\subsection{Composite Cylinder}

A picture of a composite cylinder is shown in Figure 1a. Two composite cylinders were tested. The composite cylinders' overall length is approximately $51 \mathrm{~cm}$ with an inner diameter of $8.1 \mathrm{~cm}$. The composite cylinders' thickness is tapered from the fixtures down to a uniform thickness of $0.1524 \mathrm{~cm}$. The uniform thickness represents the area of interest and is $25 \mathrm{~cm}$ in length along the tube axis as shown in Figure 1. In this area three Teflon ${ }^{\circledR}$ inserts $\mathrm{A}, \mathrm{B}$, and $\mathrm{C}$, are placed with respective sizes of $1.27 \times 1.27 \mathrm{~cm}, 0.63 \times 0.63 \mathrm{~cm}$, and $1.27 \times 1.27 \mathrm{~cm}$. The Teflon ${ }^{\circledR}$ inserts are used to simulate delamination damage and possible damage initiation sites. The top of the tube is held stationary by the torsion machine and the load is applied at the bottom with a force of $+10,000$ to $-9,000$ inch-lbs. at $4 \mathrm{~Hz}$. The axial load was held to a minimal value (target of 0 lbs.).

\subsection{Hat Stiffened Composite Panel}

The hat stiffened composite panel is shown in Figure 1b. The panel is 23 plies with a thickness of $0.64 \mathrm{~cm}$. The hat flange is 11 plies thick. Teflon ${ }^{\circledR}$ inserts were placed between the flange and skin. The Teflon ${ }^{\circledR}$ inserts were approximately $2.54 \mathrm{~cm}$ wide and were placed across opposite sides of the flange. The Teflon ${ }^{\circledR}$ inserts are used to simulate existing delamination damage and as possible damage initiation sites. Cyclic compressive loads were applied up to 54,000 pounds at 2 to $2.5 \mathrm{~Hz}$. The load is applied to the top while the bottom is held stationary. Passive thermography was used to track the damage during loading.

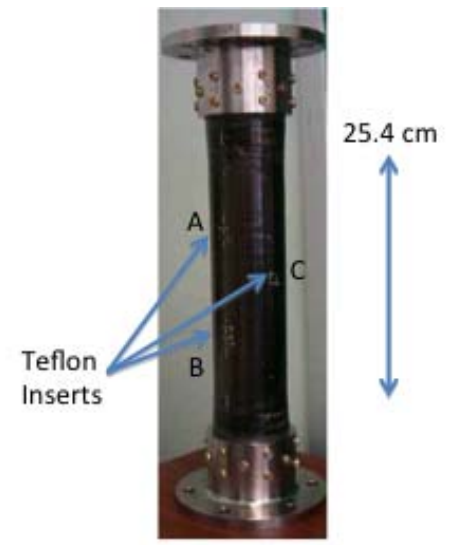

(a)

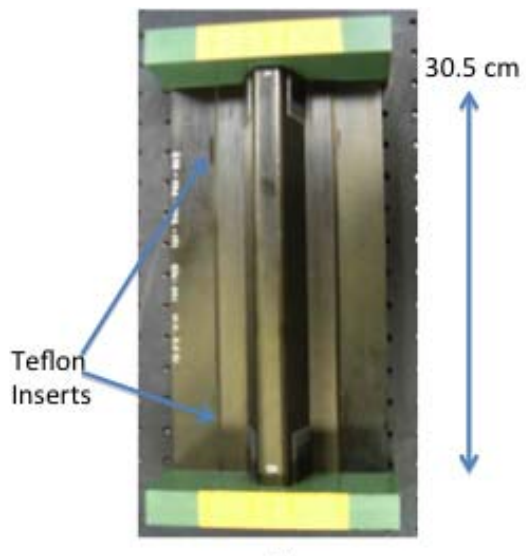

(b)

Figure 1. Composite cylinder (a) and hat stiffened panel (b) used for fatigue loading.

\section{THERMOGRAPHY SETUP}

The thermal measurement setup for both samples is shown in Figure 2. The basic system consists of an infrared (IR) camera operating in the 3-5 micrometer infrared band and an image data acquisition computer. The composite cylinder has a linear flash tube mounted within. The flash tube is approximately $19 \mathrm{~cm}$ long. The temperature rise from the flash lamp was measured within to be less than 10 degrees Celsius above ambient. The composite cylinder thermography system utilizes a pair of infrared mirrors (polished aluminum plates) to allow for a full circumference inspection in one view. The acquired data are composed of a series of 12 bit digital images with a resolution of $256 \mathrm{x} 320$ pixels captured at up to $60 \mathrm{~Hz}$ for the composite cylinder setup and $640 \times 512$ pixels captured at approximately $8 \mathrm{~Hz}$ for the hat stiffened panel setup. The passive thermography inspection did not use an externally applied heat source. The passive inspection 
captured the thermal variations during the fatigue loading. The hat stiffened panel setup required a Plexiglas ${ }^{\circledR}$ shield to contain fragments if ultimate failure occurred. The IR camera was located behind the shield with the lens positioned in front of a viewing hole. The added benefit of the shield is it also filters out spurious IR background sources.

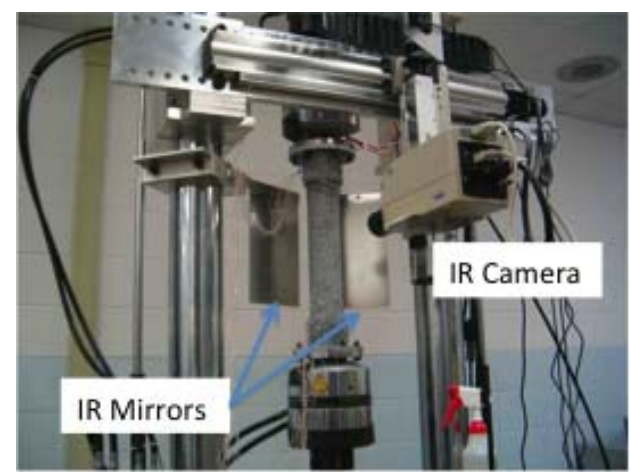

(a)

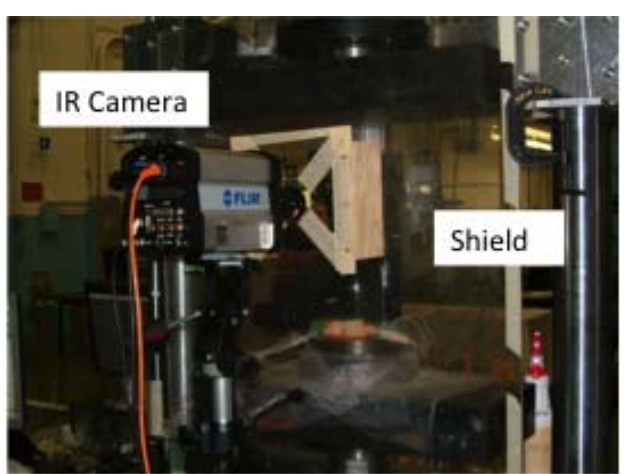

(b)

Figure 2. Composite cylinder test setup (a) and hat stiffened panel test setup (b).

\section{COMPOSITE CYLINDER INSPECTION RESULTS}

\subsection{Difference Flash Thermography}

The flash technique allows for reduction of the data into a thermal diffusivity inspection image. Any damage is measured by a change in thermal diffusivity. Thermal diffusivity images are obtained by fitting a 1-Dimensional model to the temporal thermal data pixel by pixel [4]. After a number of load cycles, typically around 50,000, a flash inspection was performed. Two flash inspections were performed: + 3,000 inch-lbs. static torsion load, and -3,000 inchlbs. static torsion load. For each static load, an effective thermal diffusivity inspection image is obtained. The effective thermal diffusivity image for the negative static load is shown in Figure 3a. The top and bottom inserts A and B are detected as compared to the effective thermal diffusivity image for the positive static load shown in Figure 3b where the top and bottom inserts, A and B, are not as apparent. For these inserts, the thermal contact resistance decreases (lower contrast) when a positive load was applied and increases (higher contrast) with a negative load. The difference in these measurements provides an image that shows all the Teflon ${ }^{\circledR}$ inserts, Figure 3c. The contact resistance change at insert A is seen in the measured temporal responses shown in Figure 4a. When a negative static load is applied, the thermal diffusivity value at inserts $A$ and $C$ decrease and the thermal diffusivity value at insert B increases, Figure $4 \mathrm{~b}$. The increases and decreases in the contact resistance, at the inserts, can be attributed to increases and decreases in the air gap. This data indicates that the response in the cylinder depends on the composite layup in the region of the inserts.

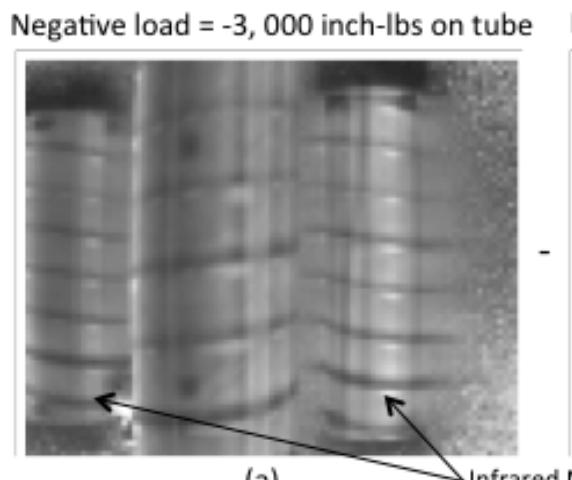

(a)

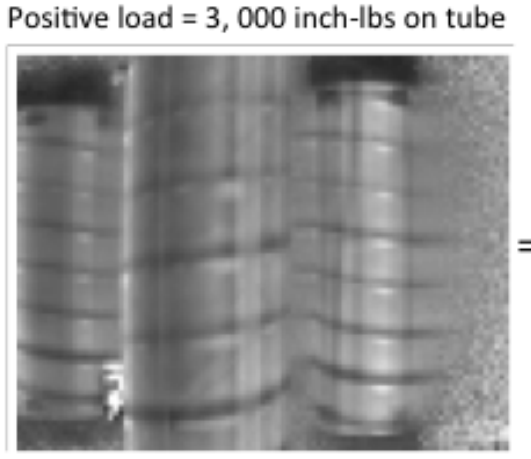

(b)

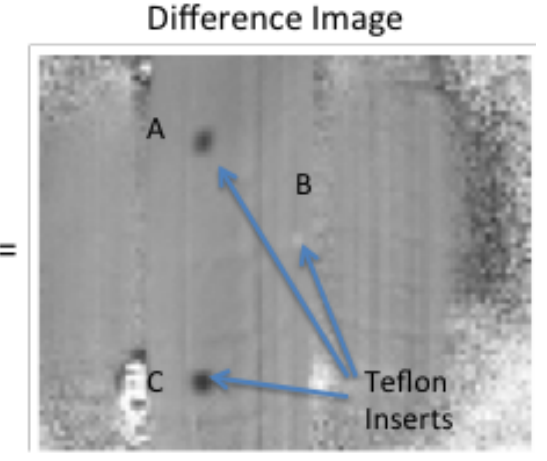

(c)

Figure 3. Difference thermal inspection. 


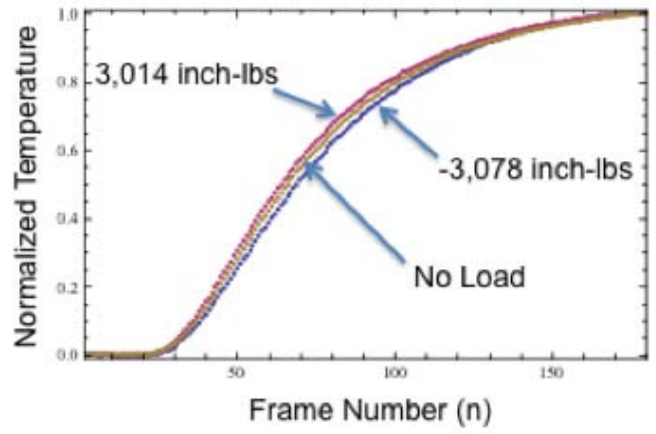

(a)

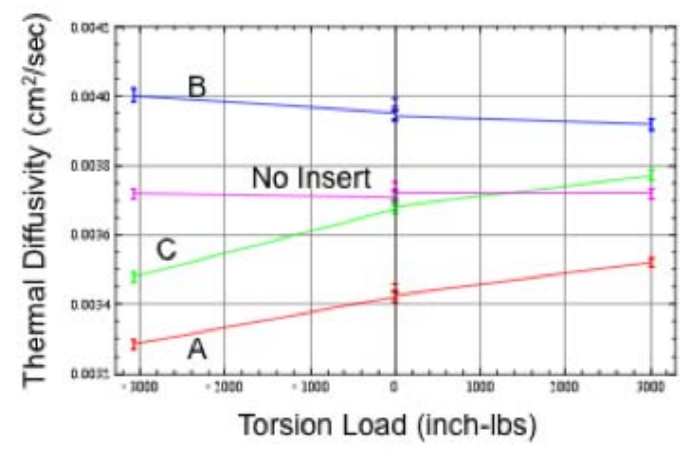

(b)

Figure 4. Change in temporal response at insert A and comparison of insert thermal diffusivity values as a function of static load.

\subsection{Air Gap Thickness Estimation}

The changes in contact resistance can be modeled as an air gap change due to the applied load. For inserts A and C the application of the negative torsion load increases the air gap, which resulted in an increase in the contact resistance. The application of a positive load decreases the air gap and thus the contact resistance, which resulted in a higher effective thermal diffusivity value. A one-dimensional model for this configuration is shown in Figure 5. The multilayered model includes the inner and outer composite layers, the insert, and air gap. The model can be solved analytically in the Laplace domain using Equation (1) where $\mathrm{V}_{2}$ is the temperature response, $\mathrm{f}_{1}$ is the instantaneous heat flux input, $l_{1}$ is the inside composite layer thickness, $\mathrm{l}_{2}$ is the outer composite layer thickness, $\mathrm{K}$ is the composite thermal conductivity, $\alpha_{\text {comp }}$ is the composite thermal diffusivity, $\mathrm{K}_{\text {Teflon }}$ is the Teflon ${ }^{\circledR}$ thermal conductivity, $\mathrm{l}_{\text {Teflon }}$ is the Teflon ${ }^{\circledR}$ thickness, $\mathrm{K}_{\mathrm{air} \text { gap }}$ is the air gap thermal conductivity, $\mathrm{l}_{\mathrm{air} \text { gap }}$ is the air gap thickness and $\mathrm{s}$ is the Laplace complex argument. A matrix equation, which represents the model, is given as:

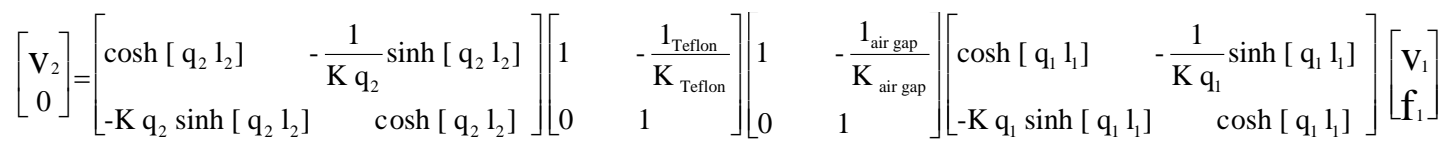

$$
\begin{aligned}
& \text { where } \quad \mathrm{q}_{2}=\mathrm{q}_{1}=\sqrt{\frac{\mathrm{s}}{\alpha_{\text {comp }}}} .
\end{aligned}
$$

The Fixed Talbot numerical inversion algorithm is used to solve for the temporal response of equation (1) [9]. The material property values used are shown in Table 1 for a nominal composite fiber volume fraction [10-12]. An

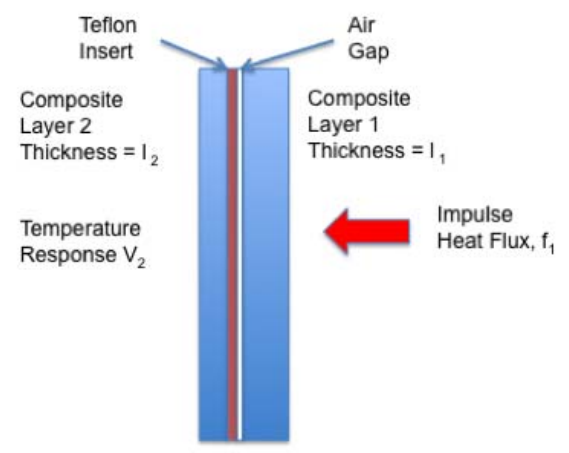

Figure 5. Multi-layered model of composite with insert and air gap. 
Table 1. Values used for curve fitting multi-layered model to the thermal data.

\begin{tabular}{|c|c|c|}
\hline Parameter & Symbol & Value \\
\hline Composite Thermal Conductivity & $\mathrm{K}$ & $0.00211 \mathrm{cal} / \mathrm{sec} / \mathrm{cm} / \mathrm{K}$ \\
\hline Composite Thermal Diffusivity & $\alpha_{\text {comp }}$ & $0.00373 \mathrm{~cm}^{2} / \mathrm{sec}$ \\
\hline Composite Layer 1 Thickness & $\mathrm{l}_{1}$ & $0.101 \mathrm{~cm}$ \\
\hline Composite Layer 2 Thickness & $\mathrm{l}_{2}$ & $0.051 \mathrm{~cm}$ \\
\hline Teflon $^{\circledR}$ Thermal Conductivity & $\mathrm{K}_{\text {Teflon }}$ & $0.000586 \mathrm{cal} / \mathrm{sec} / \mathrm{cm} / \mathrm{K}$ \\
\hline Teflon $^{\circledR}$ Thickness & $\mathrm{l}_{\text {Teflon }}$ & $0.0013 \mathrm{~cm}$ \\
\hline Air Thermal Conductivity & $\mathrm{K}_{\text {Air Gap }}$ & $0.0000614 \mathrm{cal} / \mathrm{sec} / \mathrm{cm} / \mathrm{K}$ \\
\hline Air Gap Thickness & $\mathrm{l}_{\text {Air Gap }}$ & Estimated from data fit \\
\hline
\end{tabular}

example fit to the normalized data at insert $\mathrm{A}$ is shown in Figure 6. The air gap thickness is measured with a negative static load applied. The estimated air gap thickness change at inserts A and C, due to cyclic loading is shown in Figure 7. As shown, the air gap thickness increases as the number of fatigue cycles increases. This is due to the repeated opening and closing or exercising of the air gap over the insert during cyclic loading. The air gap over insert $\mathrm{C}$ appeared to grow faster as compared to insert A. This was related to a matrix crack feature that was detected using flash thermography at insert $\mathrm{C}$ and later confirmed with passive thermography results. This is shown in the top right image in Figure 7.

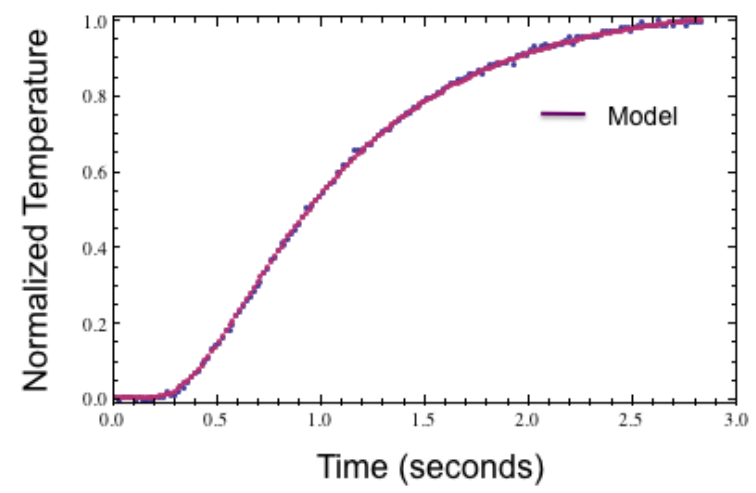

Figure 6. Multi-layered model fit to data at insert A with air gap.

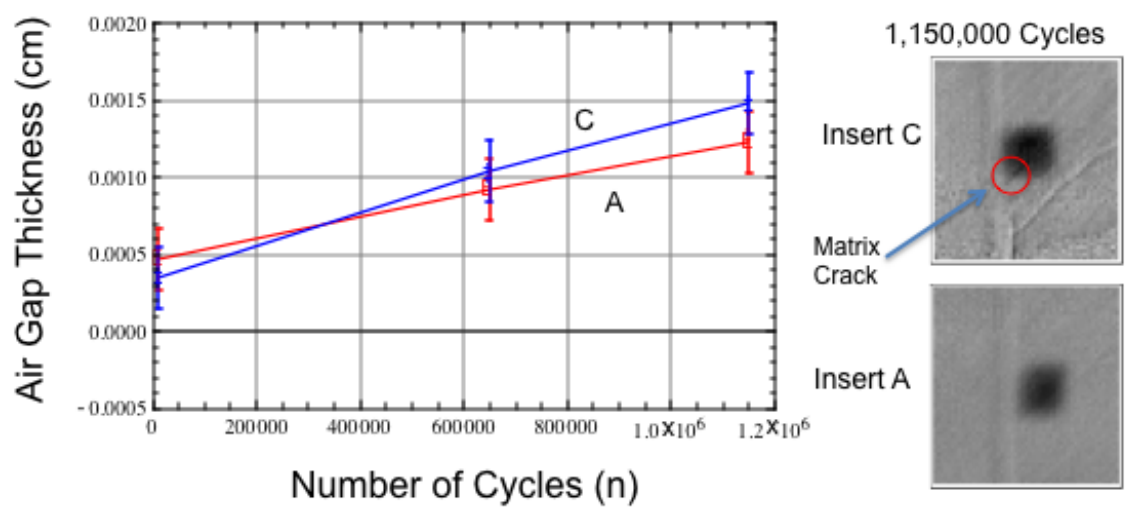

Figure 7. Estimated air gap change due to cyclic loading. 


\subsection{Early Detection and Tracking of Damage Growth}

The flash thermography difference inspection results are shown in Figure 8. Unexpectedly, the damage initiated on the right backside of the cylinder and not at the Teflon ${ }^{\circledR}$ inserts. While the UT results show greater detail, there was fairly good agreement between the non-immersion ultrasonic image and the thermography results, Figure 9. The nonimmersion inspection used an ultrasonic transducer assembly comprised of an entrapped water column with a flexible membrane for coupling [8]. The transducer assembly was mounted on the XY scanner to produce the inspection image. The ultrasonic inspection required about 2 hours to perform, and therefore, the thermography inspection (inspection time of several minutes) was used periodically to determine when an ultrasonic inspection should be performed. The ultrasonic inspection provided greater resolution of damage and at multiple interfaces (depths). There was also good agreement between the thermography image and the X-ray CT image as shown in Figure 9. The X-ray CT scan was performed using a micro-focus system with a spot size of 5 microns. No dye penetrant was required.

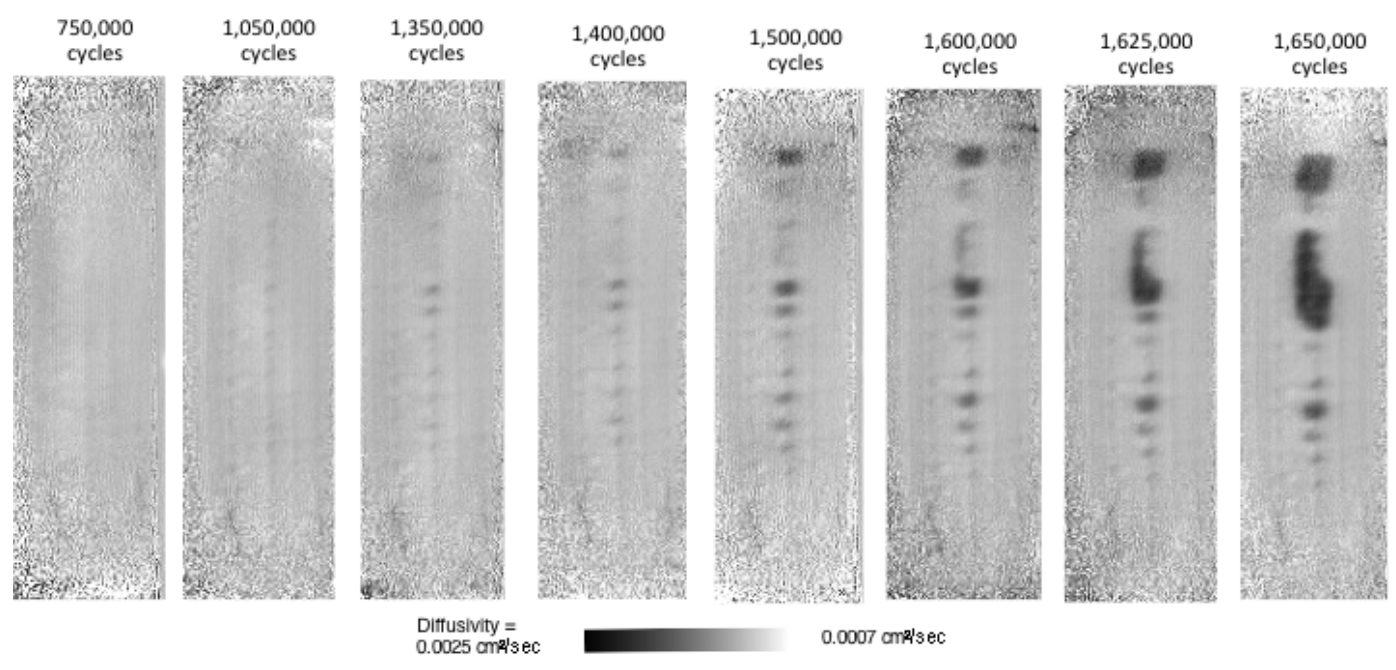

Figure 8. Difference thermography images for damage detection.

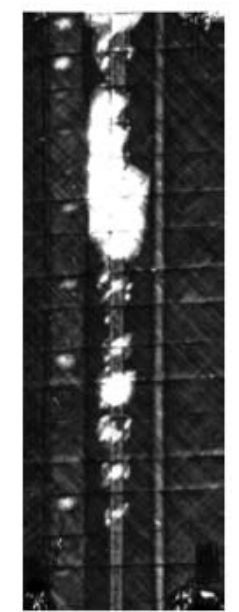

Non-Immersion UT Scan

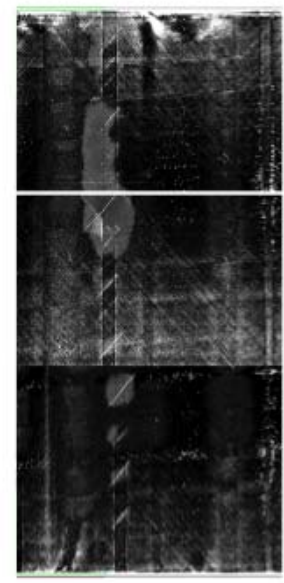

X-Ray CT

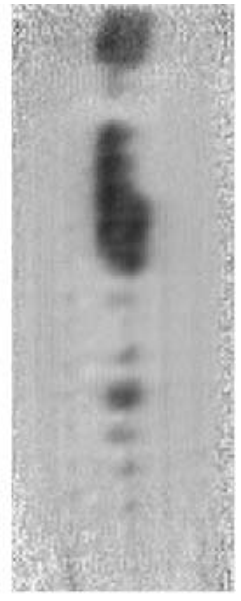

Thermography

Figure 9. Thermography inspection comparison to UT and X-ray CT (damage after 1,650,000 cycles). 


\subsection{Passive Thermography Results}

Thermal data was also taken in real time during cyclic loading on a different composite tube. The passive inspection was performed without application of external heat. Any detectable heating was a result of matrix cracks rubbing or delamination or disbond interfaces clapping or rubbing. Time domain processing using a principal component analysis data reduction algorithm was used to improve defect contrast and thus enhance visualization of the damage [13]. Examples of matrix cracks and delamination growth are shown in Figure 10 and Figure 11 respectively.

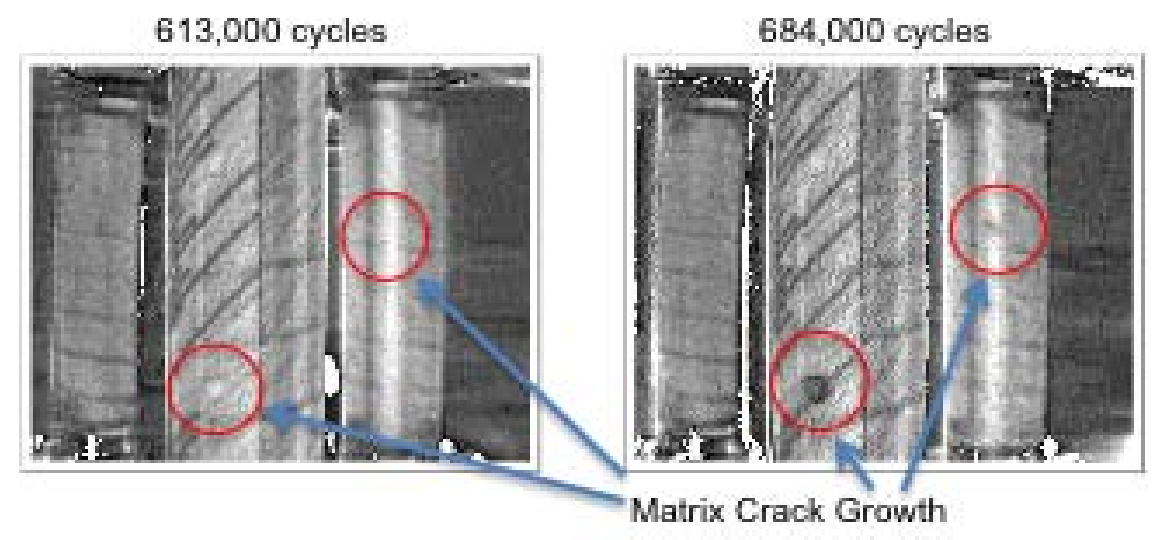

Figure 10. Example passive thermography image showing matrix crack growth.

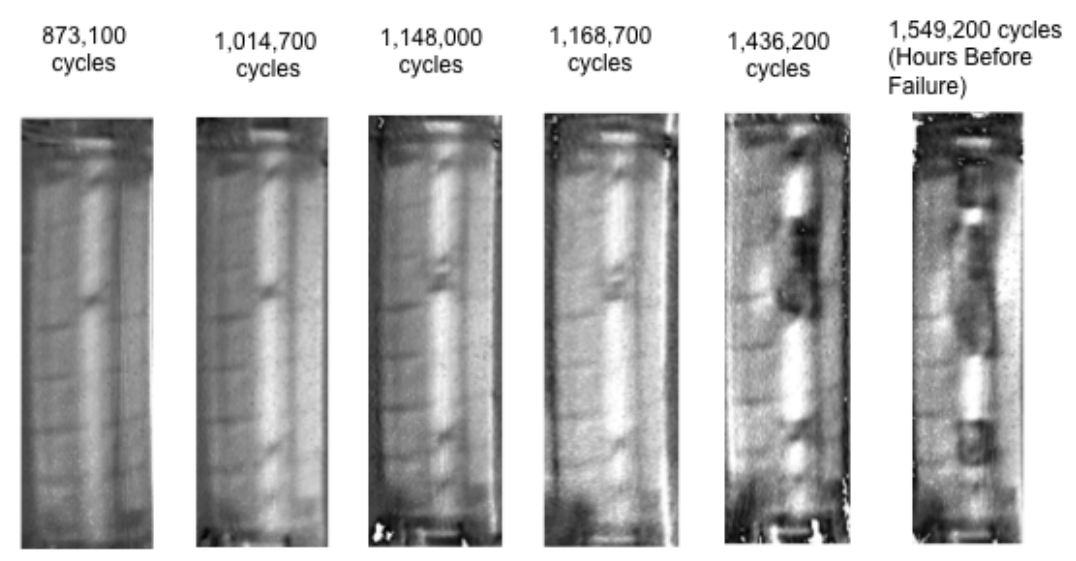

Figure 11. Passive thermography results showing damage growth.

\section{HAT STIFFENED COMPOSITE PANEL INSPECTION RESULTS}

\subsection{Passive Thermography Results}

Thermal data was also taken in real time during cyclic loading on a hat stiffened composite panel. Due to the promising results obtained previously on the composite cylinder passive measurements, custom passive thermography data acquisition software was developed. This software allows for real time processing and display of the acquired images using a multi-threaded processing capability. A real time difference imaging approach was used wherein a reference thermal image is stored and subtracted in real time. Any significant changes in temperature are easily detected. It was necessary to periodically update the reference image as the overall ambient temperature increased during fatigue loading. The custom software allowed for synchronized image acquisition with fatigue loading. The image data are stored directly to a solid-state hard drive without dropping frames. This provides the capability to acquire frames for an extended period of time (hours). Examples of passive inspection results are shown in Figure 12 along with comparisons 
to non-immersion UT. The passive thermal images show the ability to track damage as it grows in real time. Again the damage did not originate at the Teflon ${ }^{\circledR}$ insert areas. Figure 13 shows an image where the acquisition of the thermal image is perfectly timed with the catastrophic failure of the composite structure.

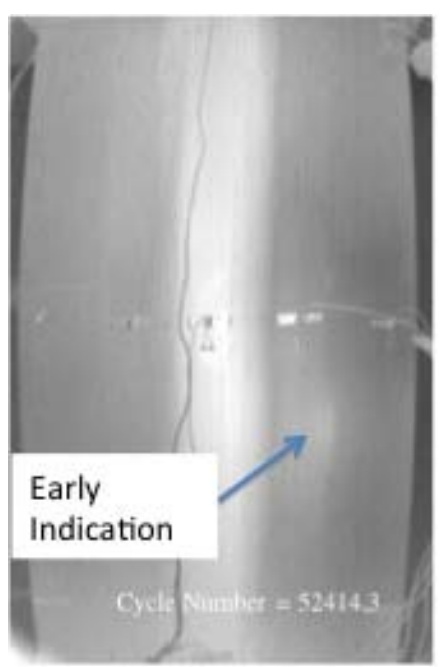

Thermography

Image around 52,400

Cycles

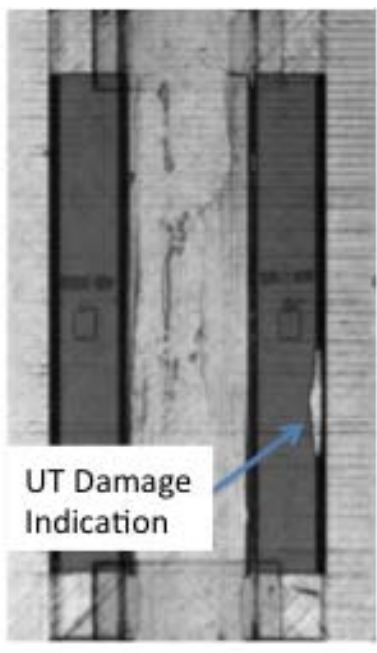

UT Scan After 55,000 Cycles

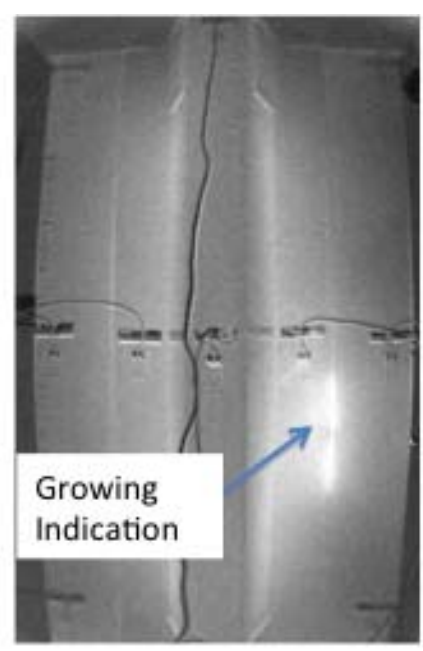

Thermography

Image around 57,500

Cycles

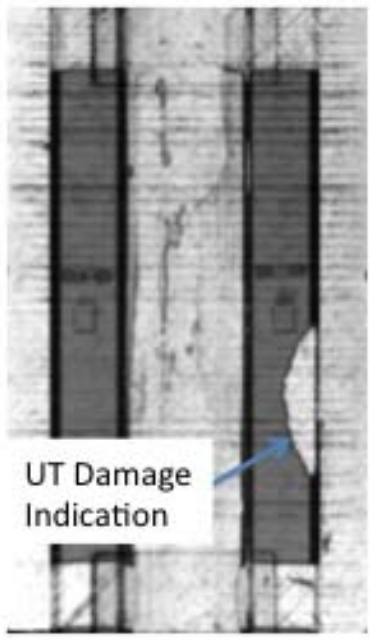

UT Scan After 57,500 Cycles

Figure 12. Passive thermography result with comparison to UT inspection.

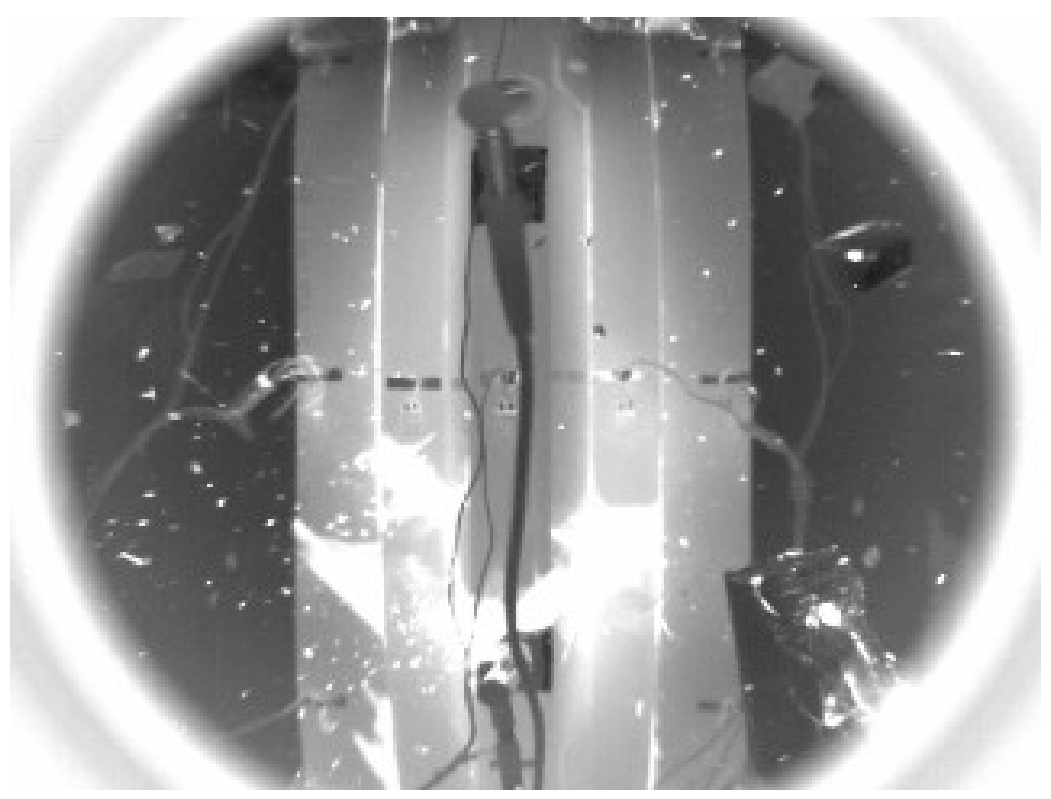

Figure 13. Passive thermography result showing damage right at moment of failure.

\section{CONCLUSIONS}

Flash thermography was used to track composite cylinder damage during cyclic fatigue testing. The combination of the difference imaging technique with application of a small torsion load on the composite cylinder demonstrated enhanced 
damage detection. Thermography results agreed with and complemented the non-immersion ultrasonic inspection and computed tomography X-ray. Passive thermography was used to track damage in a composite cylinder and a hat stiffened composite panel. The ability to do real-time inspection helps to determine damage growth, when UT inspections are performed, and provides capability to capture unexpected events.

\section{ACKNOWLEDGEMENT}

This work was performed under a NASA Space Act Agreement in cooperation with the Center for Rotorcraft Innovation. The authors would like to acknowledge William Johnston of Lockheed Martin for sample mounting.

\section{REFERENCES}

[1] T. K. O'Brien, "Development of a Delamination Fatigue Methodology for Composite Rotorcraft Structure”, NASA Aviation Safety Technical Conference Denver, CO, October 2008.

[2] R. Krueger, "An Approach to Assess Delamination Propagation Simulation Capabilities in Commercial Finite Element Codes”, NASA/TM-2008-215123, 2008.Davis, A., R., Bush, C., Harvey, J. C. and Foley, M. F., "Fresnel lenses in rear projection displays," SID Int. Symposium Digest Tech. Papers 32(1), 934-937, 2001.

[3] E. G. Henneke, K. L. Reifsnider, and W. W. Stinchcomb, Journal of Metals 31(9), 11-15, 1979.

[4] W. P. Winfree and D. M. Heath, "Thermal diffusivity imaging of aerospace materials and structures", Proceedings of SPIE, Thermosense XXIII, Vol. 3361, pp. 282-290, 1998.

[5] M. Genest, M. Martinez, N. Mrad, G. Renaud, and A. Fahr, "Pulsed thermography for nondestructive evaluation and damage growth monitoring of bonded repairs,” Composite Structures 88, 112-120, 2009.

[6] Zalameda, J. N., Winfree, W. P., Seebo, J. P., and Johnston, P. H., "Thermography Inspection for Detection and Tracking of Composite Cylinder Damage During Load Testing", REVIEW OF PROGRESS IN QUANTITATIVE NONDESTRUCTIVE EVALUATION: Volume 30A; AIP Conf. Proc. Volume 1335, pp. 450-457 June 23, 2011.

[7] William P. Winfree, Joseph N. Zalameda and Patricia A. Howell, "Improved flaw detection and characterization with difference thermography", Proc. SPIE 8013, 80130U April 2011.

[8] P. H. Johnston, C. W. Wright, J. N. Zalameda, and J. P. Seebo, "Ultrasonic monitoring of ply crack and delamination formation in composite tube under torsion load”, Ultrasonic Symposium (IUS), IEEE, pp. 595 - 598, 2010.

[9] A. Talbot, IMA Journal of Applied Math 23 (1): 97-120, 1979.

[10] J. N. Zalameda, Journal of Composite Technology and Research 21, 98-102, 1999.

[11] Air Properties The Engineering Toolbox, www.engineeringtoolbox.com/air-properties-d_156.html.

[12] Teflon ${ }^{\circledR}$ Specifications, Boedeker Plastics, Inc., www.boedeker.com/teflon_p.htm.

[13] N. Rajic, Composite Structures 58, 521-528, 2002. 